J Ästhet Chir 2009 · 2:114-114 DOI 10.1007/s12631-009-0044-9

Online publiziert: 28. Juni 2009

(c) Springer Medizin Verlag 2009

H.G. Bull1, 2

${ }^{1}$ St. Josefshospital Uerdingen, Krefeld

${ }^{2}$ Geschäftsstelle der Gesellschaft für Ästhetische Chirurgie Deutschland (GÄCD), Bad Soden a. T.

\title{
Einladung zum Jahreskongress in Köln
}

Sehr geehrte Frau Kollegin, sehr geehrter Herr Kollege,

vom 22. bis zum 24. Oktober 2009 findet in Köln unter der Jahrespräsidentschaft von Herrn Dr. Zia Taufig die 22. Jahrestagung der Gesellschaft für Ästhetische Chirurgie Deutschland statt.

Die Jahrestagung stellt wie immer einen Höhepunkt des klinischen und wissenschaftlichen Austauschs sowie der interdisziplinären Diskussion dar.

Deshalb möchte ich Sie noch einmal auf diesem Weg sehr herzlich nach Köln einladen.

Wir kooperieren bei unserem Jahreskongress mit den Beneluxstaaten als Partnerländer.

Wie in den letzten beiden Jahren möchten wir mit dieser Partnerschaft unsere internationalen Kontakte ausweiten und heißen daher unsere Kollegen aus den Nachbarländern zu unserem Kongress besonders herzlich willkommen.
Bis zum Jahreskongress in Köln wünsche ich Ihnen eine angenehme Sommerzeit und viel Freude bei der Lektüre unseres Journals für Ästhetische Chirurgie.

Ihr

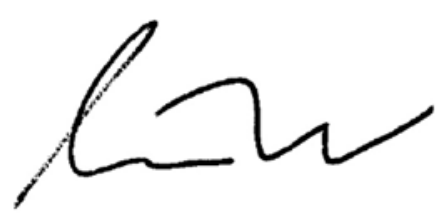

Prof. Dr. Dr. med. H.G. Bull Präsident der GÄCD

\section{Korrespondenzadresse \\ Prof. Dr. Dr. H.G. Bull \\ St. Josefshospital Uerdingen \\ Kurfürstenstraße 69, \\ 47829 Krefeld \\ bull.mkg@stjosef.de}

\section{Übersicht Leitthemen}

\section{9}

1/2009 Filler

2/2009 Chirurgie des alternden Gesichts (Teil 1)

3/2009 Chirurgie des alternden Gesichts (Teil 2), Nasenchirurgie

4/2009 Lidchirurgie

2010

$1 / 2010$ Filler und Botulinustoxin

2/2010 Otoplastik

3/2010 Mammachirurgie

4/2010 Fettabsaugung, Bauchdeckenplastik 